\title{
DA GARANTIA DOS DIREITOS TRABALHISTAS DO PROFESSOR COMO INSTRUMENTO DE VALORIZAÇÃO DA EDUCAÇÃO
}

ROCCO ANTONIO RANGEL ROSSO NELSON INSTITUTO FEDERAL DO RIO GRANDE DO NORTE - IFRN

RAFAEL LAFFITTE FERNANDES INSTITUTO FEDERAL DO RIO GRANDE DO NORTE - IFRN

MARIA SOARES DE MACÊDO INSTITUTO FEDERAL DO RIO GRANDE DO NORTE - IFRN 


\title{
RESUMO
}

Recibido: 12/06/2013

Aceptado: 20/12/2013

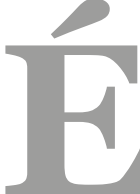

sabido que o ordenamento brasileiro abarca inúmeras normas protetivas ao trabalhador, havendo preceitos específicos em relação a certas profissões, como é o caso do professor. É ululante que o desrespeito dessas normas imperativas de cunho social é corriqueiro pela entidade privada, desejoso pelo lucro rápido e avantajado. Dessa mazela padece as Instituições de Ensino Superior privado do Brasil. A pesquisa em tela, fazendo uso de uma metodologia de análise qualitativa, usando-se os métodos de abordagem hipotético-dedutivos de caráter descritivo e analítico, tem por linha de fundo colacionar os dispositivos normativos de cunho trabalhista ou que interfere na relação laboral, regente da atividade do professor de ensino fundamental, médio e superior, bem como expor esses direitos a luz dos tribunais e de uma doutrina consagrada.

Palavras-Chave: Revalorização do professor, Direitos Trabalhistas, Efetivação.

\section{RESUMEN}

Es sabido que el ordenamiento jurídico brasilero abarca un sinnúmero de normas protectorias del trabajador, habiendo preceptos específicos con relación a ciertas profesiones, como es el caso del profesor. Es alarmante que la falta de observación de esas normas imperativas de raigambre social sea habitual en las entidades privadas, con el objetivo de obtener ganancias rápidas y a costa de los derechos violados. De este actuar contrario a la ley también son parte las Instituciones de Enseñanza privada del Brasil. La presente investigación, haciendo uso de una metodología de análisis cualitativa, y usando como métodos de abordaje el hipotético-dedutivo de carácter descriptivo y analítico, tiene por objetivo resaltar las normas laborales o de otra naturaleza que tienen aplicación a la relación laboral de los profesores de enseñanza primaria, secundaria y universitaria, resaltando cómo esos derechos son aplicados e interpretados por los tribunales y los doctrinarios de renombre.

Palabras Clave: Revalorización de la profesión docente, Derechos del trabajador, Efectivización.

\begin{abstract}
It is known that the Brazilian legal system encompasses numerous protective standards to the worker, with specific provisions for certain professions, such as teacher. It is blindingly disrespect that these mandatory rules of social is commonplace for private, eager for quick
\end{abstract}


profit and topping. This illness suffers the Private Higher Education Institutions in Brazil. Research on the screen, making use of a method of qualitative analysis, using the methods of hypothetical-deductive approach of descriptive and analytical, is the bottom line collate devices normative imprint labor or interfering in the employment relationship, conductor activity teacher primary, secondary and higher education, as well as exposing the light of these rights courts and a doctrine enshrined.

Keywords: Revaluation teacher, Labor Rights, Effectiveness.

\section{CONSIDERAÇÕES INICIAIS}

Tendo em vista a busca constante da revalorização do professor, na qual reflete na garantia de remunerações e condições de trabalho condignas, como bem prevê o projeto do Plano Nacional de Educação (2011-2020), (Dourado, 2011, p. 52), tornando-se fulcral a luta constante, por tal desiderato, como um dos fatores para elevar a educação no país, seja evitando o êxodo dos bons mestres, seja estimulando a entrada de novos talentos, além de melhoria na qualidade do ensino, tendo em vista que cessaria as jornadas intermináveis do docente em várias instituições, nos mais diversos horários (Aranha, 2012, p. 300).

O presente trabalho busca analisar os dispositivos normativos e as decisões dos tribunais que respaldam as garantias justrabalhistas do professor, fazendo uso de uma metodologia de análise qualitativa, usando-se os métodos de abordagem hipotético-dedutivos de caráter descritivo e analítico.

Não há dúvida que para poder analisar os dispositivos normativos que guarnecem esse trabalhador, é fulcral conceituar o que seja a figura do professor. A legislação pátria não o define. Averbe-se o conceito dado por Barros, que abrange os vários níveis de atuação (educação básica, superior, profissionalizante), granjeando o magistério em cursos livres, além de avocar sua importância no desenvolvimento do país.

Assevera Barros (2012):

Em face dessas particularidades, entendemos como professor o profissional, habilitado ou autorizado, que, por meio das atividades inerentes ao magistério, forma as gerações do país propiciando-lhes a educação básica e magistério, forma as gerações do país propiciando-lhes a educação básica e superior, ou complementando-lhes a formação em curso de especialização, técnico, preparatório ou profissionalizante, realizados em estabelecimento de ensino público, particular, livre, ou ainda em outro estabelecimento que', embora não específico, proporcione essa formação. (p. 368) 


\section{DOS DIREITOS E GARANTIAS EM ESPÉCIE DO PROFESSOR \\ 2.1. JORNADA DE TRABALHO}

Jornada de trabalho na definição de MARTINS (2004, p. 437) “diz respeito ao número de horas diárias de trabalho que o trabalhador presta a empresa".

O dispositivo normativo da Consolidação das Leis do Trabalho determinou a carga horária para o professor de ate 4 horas/aula, consecutivas, ou seis horas/aula, de forma intercalada. ${ }^{1}$ Esse tratamento diferenciado da jornada de trabalho dar-se pelo desgaste físico e mental que essa categoria possui, em particular.

Atente que o art. 318 da Consolidação das Leis do Trabalho, ${ }^{2}$ ao explicitar sobre o quantum da hora aula do professor, determina que o mesmo não possa prestar àquelas horas/aula ${ }^{3}$ para o mesmo estabelecimento de ensino.

É necessário, aqui, fazer uma interpretação teleológica, pois o fim do legislador foi proteger o professor de uma jornada de trabalho prolongada ao mesmo empregador, apesar de falar em estabelecimento. Ou seja, a prestação consecutiva superior a 4 horas-aula é possível desde que feito por empregadores diversos ${ }^{4}$.

Caso interprete de forma diversa, isso permite um rasgo normativo, na qual o empregador, com mais de um estabelecimento, exploraria o mesmo professor, vindo, assim, a burlar o fim protetivo que buscou a lei.

O artigo supra, aplica-se a professores, seja do ensino fundamental, ao médio, superior e pós-graduação. Todavia, essa norma não se estende para as atividades de ensino fora da dimensão regulada pelo Ministério da Educação, como cursos preparatórios, de dança, línguas, etc ${ }^{5}$.

\footnotetext{
${ }^{1}$ Art. 318 - Num mesmo estabelecimento de ensino não poderá o professor dar, por dia, mais de 4 (quatro) aulas consecutivas, nem mais de 6 (seis), intercaladas.

${ }^{2}$ Consolidação das Leis do Trabalho. Decreto-lei n.o 5.452, de 1ㅇ de maio de 1943. Aprova a Consolidação das Leis do Trabalho. Diário Oficial da União. Brasília, DF, 09 de agosto de 1943. Disponível em: http://www.planalto.gov.br/ccivil_03/decreto-lei/ del5452.htm. Acesso em: 20 de fevereiro de 2012.

${ }^{3}$ Quatro horas/aula, consecutivas, ou seis horas/aula, de forma intercalada.

4 "Com inteiro contrassenso ao regime de dedicação, a CLT, no art. 318, veda que o professor ministre mais de quatro aulas consecutivas ou seis intercaladas em um mesmo estabelecimento de ensino, não vedando que o profissional possa partir de um lado para outro da cidade, expondo-se a risco, gastando a mais com a locomoção, para ministrar aula em outra instituição". (Mello, 2010, p. 199).

${ }^{5}$ RECURSO DE REVISTA. INSTRUTOR TÉCNICO DO SENAI. ENQUADRAMENTO SINDICAL. As finalidades e os objetivos específicos das entidades que compõem o Sistema -S-, entre elas, o Serviço Nacional de Aprendizagem Industrial - SENAI (nos termos das legislações pertinentes, inclusive da Lei no 9.394/1996), não se confundem com aqueles da educação regular, aspecto esse que enquadra as referidas entidades no $2 \circ$ Grupo das Empresas de Difusão Cultural e Artística, no Plano da Confederação Nacional de Educação e Cultura, e não no 1ำ Grupo dos Estabelecimentos de Ensino, a teor do que dispõe o art. 570 da CLT. Por sua vez, os instrutores de ensino profissionalizante das referidas entidades são profissionais qualificados para o treinamento e o aperfeiçoamento profissional - em se tratando do SENAI, no campo industrial - não se incluindo na categoria diferenciada dos professores, mormente se não atendem aos requisitos do art. 317 da CLT. Nesse contexto, e em face do paralelismo simétrico que deve existir entre as categorias econômica e profissional, conforme o quadro das atividades e profissões a que se refere o art. 577 consolidado, a representatividade dos instrutores do SENAI e de outras entidades similares cabe aos sindicatos dos trabalhadores em entidades culturais, recreativas, de assistência social, de orientação e formação profissional das respectivas localidades. Recurso de revista conhecido e não provido. (Tribunal Superior do Trabalho. OITAVA TURMA, Recurso de Revista 158000-57.2008.5.12.0035, relator Ministro Dora Maria da Costa, Diário Eletrônico da Justiça do Trabalho, 03/06/2011).
} 
É fulcral não confundir hora com hora-aula, os mesmos não são sinônimos. A hora é uma unidade de medida de tempo que equivale há sessenta minutos, o qual se refere à vigésima quarta parte de uma de um dia solar' ${ }^{6}$ Já a hora-aula é um critério normativo para aferir o salário-hora do professor, tendo fins estritamente acadêmicos.

A Lei de Diretrizes e Base da Educação ${ }^{7}$ buscou um padrão de qualidade mínimo, em âmbito nacional, estabelecendo, por exemplo, em relação ao ensino fundamental e médio, uma carga horária mínima anual de 800 horas-ano, o que equivale a 2400 horas anuais, tendo em vista que a hora equivale a 60 minutos (Cassar, 2011, p. 697).

No projeto pedagógico do estabelecimento de ensino ira determinar a quantidade horas por disciplina, ficando a critério do respectivo projeto, estabelecer a duração da hora-aula (Cassar, 2011, p. 697).

Ou seja, dependendo do projeto pedagógico de cada estabelecimento, pode haver horaaula de 60 minutos, 55 minutos, 50, minutos, etc. Em face dessa hora-aula, serão determinadas quantas aulas ocorrera na disciplina.

Por exemplo, numa disciplina de 60 horas, como hora-aula de 45 minutos, deve ocorrer a realização de 80 aulas.

A partir dessa diferença, fundamental, entre hora e hora-aula, determina-se, como consequência jurídica, que se o professor ministrar mais de quatro horas-aula (variável segundo o projeto pedagógico da instituição de ensino), consecutivas, fara jus ao adicional de hora-extra (50\%).

Entretanto, respeitado o intervalo intrajornada de seis horas-aula, no dia, como determina o art. 318 da Consolidação das Leis do Trabalho ${ }^{9}$, o professor não fara jus a respectiva hora extra ${ }^{10}$.

\footnotetext{
6"Na verdade, a hora é um segmento de tempo equivalente a 60 minutos e estabelecido a partir da vigésima quarta parte de um dia solar ou do tempo em que o planeta Terra leva para girar em torno de si mesmo. A hora de 60 minutos, como lembra o Parecer Conselho Nacional de Educação/Câmara de Educação Superior supracitado se apoia em dispositivos legais nacionais e internacionais. O Observatório Nacional, órgão vinculado ao Ministério da Ciência e Tecnologia tem, entre seus objetivos, o de zelar pela hora legal brasileira e manter sob sua guarda os padrões nacionais de frequência em articulação com o INMETRO. A hora legal brasileira se apoia no Tratado de Greenwich pelo qual o meridiano que passa na cidade de Londres foi tomado como meridiano padrão e ponto de partida para o cálculo da longitude terrestre. Como tal, isto possibilitou a divisão da longitude terrestre em 24 divisões imaginárias em forma de fusos geométricos e cujos pontos possuem, em princípio, a mesma hora legal. Após a Conferência Internacional de Paris, em 1912, o Brasil, que se abstivera em 1884, em Washington, aderiu definitivamente ao Tratado de Greenwich, como se pode ler na Lei 2.784 de 18/6/1913...". Cf. BRASIL. Ministério da Educação. Conselho Nacional de Educação. Parecer no 08/2004, p. 02-03. Disponível em: http://www.cref6.org.br/arquivos/parecer.pdf. Acessado em: 09 de novembro de 2011.

${ }^{7}$ Lei de Diretriz e Bases da Educação. Lei no 9.394, de 20 de dezembro de 1996. Estabelece as diretrizes e bases da educação nacional. Diário Oficial da União. Brasília, DF, 23 de dezembro de 1996. Disponível em: http://www.planalto.gov.br/ccivil_03/ leis/I9394.htm. Acesso em: 18 de julho de 2012.

${ }^{8}$ Consolidação das Leis do Trabalho. Art. 71. § 4ㅇ Quando o intervalo para repouso e alimentação, previsto neste artigo, não for concedido pelo empregador, este ficará obrigado a remunerar o período correspondente com um acréscimo de no mínimo $50 \%$ (cinquenta por cento) sobre o valor da remuneração da hora normal de trabalho. (Junior, 2011, p. 293).

${ }^{9}$ Art. 318 - Num mesmo estabelecimento de ensino não poderá o professor dar, por dia, mais de 4 (quatro) aulas consecutivas, nem mais de 6 (seis), intercaladas.

${ }^{10}$ Orientação jurisprudencial - seção de dissídios individuais 1-206 PROFESSOR. HORAS EXTRAS. ADICIONAL DE 50\% (inserida em 08.11.2000) Excedida à jornada máxima (art. 318 da CLT), as horas excedentes devem ser remuneradas com o adicional de, no mínimo, 50\% (art. 7o, XVI, CF/1988).
} 
Essa hora-extra não se enquadra no trabalho extraclasse realizado pelo professor, como na elaboração de planos de aula, correção de provas, etc. Esse trabalho já esta inclusa no valor da hora-aula. Destarte, nada impedi que acordo coletivo fixe adicional de atividade, para remunerar as atividades extraclasses.

Em relação a matéria acima, dispõe o julgado do Tribunal Superior do Trabalho:

\section{RECURSO DE REVISTA - PROFESSOR - HORA ATIVIDADE - SERVIÇOS EXTRACLASSE - REMUNERAÇÃO. O tempo destinado pelo professor à elaboração de estudos, planejamento e avaliação do aluno e do conteúdo programático já está incluído na carga horária do educador, sendo que tais atividades encontram-se remuneradas dentro dos valores pagos pelas horas-aulas semanais. Nesse sentido são os arts. 320 da CLT e 67, V, da Lei no 9.394/96 (Lei de Diretrizes e Bases da Educação Nacional) ${ }^{11}$.}

Todavia, as horas destinadas a reuniões, cursos, sanando dúvidas de alunos, realizadas fora do horário de aula, isso sim, dá ensejo à hora extra, pois o professor encontra-se a disposição da Instituição de ensino (Barros, 2011, p. 565).

Atente que no caso de professor aplica-se a redação do art. 71 da Consolidação das Leis do Trabalho, visto que não houve exclusão expressa e nem se trata de norma especial. Assim, para a atividade que não ultrapassa 6 horas diárias, e garantidas ao professor o intervalo de 15 minutos (Cassar, 2011, p. 699), quando ultrapassar 4 horas-aula ${ }^{12}$.

Perceba que esse dispositivo normativo coaduna-se com a redação do art. 318 da Consolidação das Leis do Trabalho, quando o mesmo que determina a jornada máxima de 6 horas-aula, ao professor, para o mesmo empregador, desde que intercalado, ou seja, descontínuo.

Esse intervalo, o qual não será remunerado ${ }^{13}$, tem por fito uma questão de proteção à saúde do trabalhador, pois permite o repouso e alimentação do professor, não podendo se excluído, nem mesmo por acordo ou convenção coletiva.

A não obediência a esse intervalo mínimo pelo empregador ensejará a remuneração desse intervalo como hora-trabalhada com adicional de 50\%, segundo o art. $71, \S 4^{\circ}$ da Consolidação das Leis do Trabalho (Cassar, 2011, p. 697).

Essa ficção legal visa proteger o trabalhador contra os abusos do poder econômico, cometidos pelo empregador, independentemente das atribuições ou do local onde se encontra o trabalhador (dentro ou fora do estabelecimento).

\footnotetext{
${ }^{11}$ A Tribunal Superior do Trabalho, 4a Turma, Recurso de Revista 23400-18.2008.5.04.0231, Relator Ministro Luiz Philippe Vieira de Mello Filho, Diário Eletrônico da Justiça do Trabalho, 01/03/2013.

${ }^{12}$ Consolidação das Leis do Trabalho. Art. 71. § 1ㅇ - Não excedendo de 6 (seis) horas o trabalho, será, entretanto, obrigatório um intervalo de 15 (quinze) minutos quando a duração ultrapassar 4 (quatro) horas.

${ }^{13}$ Consolidação das Leis do Trabalho. Art. 71. § 2o - Os intervalos de descanso não serão computados na duração do trabalho.
} 
Nos precedentes do Tribunal Superior do Trabalho constata-se que o mesmo não obedeceu à regra geral de um salário mínimo proporcional a jornada de trabalho, garantindo ao professor o salário mínimo de forma integral.

Assim, ao professor é garantido um salário mínimo, integral, pela jornada de trabalho de seis horas-aula dia, não havendo a sua redução proporcional, como aplicado aos demais empregados.

Afira que esse entendimento vai de encontro a outros precedentes do próprio Tribunal Superior do Trabalho, cabendo argumentos de inconstitucionalidade, por violação do principio da isonomia ${ }^{14}$.

Julgado do Tribunal Superior do Trabalho que corrobora tal afirmação:

PROFESSOR - SALÁRIO MENSAL INFERIOR AO MÍNIMO LEGAL. O professor possui uma situação especial e peculiar, porquanto, ainda que se trate de profissional competente e com longos anos de experiência, terá necessariamente que despender boa parte do seu tempo com outras atividades relacionadas ao seu mister, tais como a preparação das aulas, correções de provas, entre outras. Daí porque, mesmo que tenha sido contratado para uma jornada de quatro horas diárias, revela-se não só justo mas também constitucionalmente previsto o percebimento mensal de, pelo menos, o valor equivalente a um salário-mínimo, à luz do que preconiza o artigo $7^{\circ}$, IV, da Constituição Federal. Recurso de revista provido" (TST-RR-401.976/1997.6, Rel. Min. Wagner Pimenta, publicado no DJ de 08.02.2002).

\subsubsection{INTERVALO INTERJORNADA}

Ointervalo interjornada seria o tempo de descanso entre uma jornada e outra, o qual, segundo o art. 66 da Consolidação das Leis do Trabalho ${ }^{15}$ deve ser de no mínimo 11 horas consecutivas.

A categoria dos professores é uma categoria diferenciada, a qual possui regras próprias sobre a jornada laboral, disposta nos art. 318 a 321 da Consolidação das Leis do Trabalho. Todavia, quando não existir disposição especifica, a respectiva categoria segue os regramentos gerais da Consolidação das Leis do Trabalho' ${ }^{16}$.

\footnotetext{
${ }^{14}$ Orientação jurisprudencial - seção de dissídios individuais 1 -358 SALÁRIO MÍNIMO E PISO SALARIAL PROPORCIONAL Ȧ JORNADA REDUZIDA. POSSIBILIDADE (DJ 14.03.2008) Havendo contratação para cumprimento de jornada reduzida, inferior à previsão constitucional de oito horas diárias ou quarenta e quatro semanais, é lícito o pagamento do piso salarial ou do salário mínimo proporcional ao tempo trabalhado.

${ }^{15}$ Consolidação das Leis do Trabalho. Art. 66 - Entre 2 (duas) jornadas de trabalho haverá um período mínimo de 11 (onze) horas consecutivas para descanso.

${ }^{16}$ INTERVALO INTERJORNADA. ART. 66 DA CLT. APLICABILIDADE AO PROFESSOR. PROVIMENTO. Esta Corte tem se posicionado no sentido de que os arts. 317 a 324 da CLT, que tratam das disposições especiais sobre duração e condições de trabalho dos professores, não excluem o direito dos professores ao intervalo interjornada. Precedentes. Recurso de Revista conhecido e provido." (Recurso de Revista-1524600-56.2002.5.09.0651, Relatora Ministra: Maria de Assis Calsing, 4a Turma, Diário Eletrônico da Justiça do Trabalho, 06/08/2010 - trecho da ementa).
} 
De tal sorte, no caso de descumprimento do intervalo mínimo de descanso de 11 horas, entre uma jornada e outra, acarreta direito ao professor a horas extras. Lembrar que tais normas são imperativas, não sujeitas à negociação ou renúncia, por tratar de prescrições que buscam proteger a saúde e a segurança do trabalhador ${ }^{17}$.

Segue jurisprudência aplicando tal normativa:

INTERVALO INTERJORNADA. PROFESSOR. A jurisprudência do TST firmouse no sentido de que o direito ao intervalo interjornada aplica-se à categoria dos professores. Em assim sendo, o desrespeito ao referido intervalo redunda na condenação ao pagamento de horas extras, ao teor da Orientação Jurisprudencial $\mathrm{n}^{0}$ 355, da Seção de Dissídios Individuais -1, do Tribunal Superior do Trabalho. Precedentes. Recurso de revista de que não se conhece ${ }^{18}$.

Seria o caso do professor que ministra aula, numa instituição de ensino, até às $22 \mathrm{~h} 20 \mathrm{~min}$ horas e tem que ministrar aula, no dia seguinte, na mesma instituição, às $07 \mathrm{~h} 00 \mathrm{~min}$ horas. Perceba que o professor só teve, apenas, ogh4omin horas de descanso de uma jornada de trabalho para outra, fazendo jus à hora-extra, em relação à 01h20min hora.

Tal ilação confirma-se com o julgado abaixo:

RECURSO DE REVISTA. INTERVALO INTERJORNADA - HORAS EXTRAORDINÁRIAS. Os arts. 317 a 324, que tratam das disposições especiais sobre duração e condições de trabalho dos professores, em nenhum momento exclui o direito dos professores ao intervalo interjornada. Embora não haja norma similar a do intervalo intrajornada para a situação de desrespeito ao intervalo mínimo entre as jornadas de trabalho, o ressarcimento do obreiro pela supressão desse intervalo interjornada é medida que se impõe. Assim, o desrespeito ao intervalo mínimo de onze horas entre as jornadas de trabalho enseja a recomposição do prejuízo causado ao obreiro, remunerando-o com horas extraordinárias quando não observado o intervalo interjornada estabelecido no artigo 66 da CLT. Exegese do artigo 71, $\S 4 .^{\circ}$, da CLT e da Súmula n. ${ }^{\circ} 110$ dessa C. Corte Superior. Recurso de revista conhecido e provido".19

\footnotetext{
17 “A não-observância do intervalo entre duas jornadas previsto nos artigos 66 e 67 da CLT causa prejuízo diretamente ao trabalhador, ensejando merecida reparação pecuniária, em atenção ao escopo protetivo da integridade física e mental do trabalhador, que necessita daquele período de descanso mínimo para poder recuperar suas energias, bem como forma de desestimular a reincidência dessa atitude empresarial, praticada em desrespeito às normas mínimas de proteção e segurança do trabalho". "...o horário das aulas era de terça a sexta-feira de 19 às 22:40 horas e aos sábados, de forma alternada, de 07:20 às 16:20/16:30 horas; que o reclamante ministrava aulas no horário noturno e nos sábados..." (fl. 112), faz jus o autor ao pagamento de mais 4h: 40min (quatro horas e quarenta minutos) extras por mês durante todo o pacto laboral." (Cf. Tribunal Regional do Trabalho 3o Região, SEGUNDA TURMA, Recursos Ordinário no 00461-2008-090-03-00-7, relator desembargador Anemar Pereira Amaral, Diário de Justiça da União 18.05.2009, p.156).

18 Tribunal Superior do Trabalho. Recurso de Revista - 1093-14.2010.5.03.0139. Relatora Ministra: Kátia Magalhães Arruda, 6a Turma, Diário Eletrônico da Justiça do Trabalho, 08/03/2013.

${ }^{19}$ Tribunal Superior do Trabalho. 6. a Turma ,recurso de revista no 767100-05.2001.5.09.0006, Relator Ministro Aloysio Corrêa da Veiga, 6. a Turma, Data de Publicação: 21/8/2009.
} 


\subsubsection{DAS “JANELAS"}

As “janelas" são o tempo compreendido a disposição do empregador, na qual o professor fica no aguardado de uma aula para outra. Por esse tempo, computasse como hora-aula trabalhada, devendo o mesmo ser remunerado ${ }^{20}$.

Tal circunstância é algo corriqueiro da docência, quando o professor ministra aula, por exemplo, nos dois primeiros horários, tendo que esperar o terceiro horário (livre), para ministra a sua aula que acontece no quarto horário. Ou seja, é um horário que o mesmo fica a disposição da instituição, pois como a fração de tempo é exígua, não compensando ao docente ir para casa ou praticar algum ato de descanso, devendo ser remunerado pelos quatro horários (3 horários de aula e uma "janela") (Barros, 2011, p 566).

Segue, abaixo, o precedente normativo da seção de dissídios coletivos do Tribunal Superior do Trabalho, respaldando o direito ao recebimento da "janela", ao professor:

\section{Seção de Dissídios Coletivos - Parecer Normativo no 31 PROFESSOR (JANELAS)}

Os tempos vagos (janelas) em que o professor ficar à disposição do curso serão remunerados como aula, no limite de 1 (uma) hora diária por unidade.

\subsubsection{HORÁRIO DO RECREIO}

O horário de internvalo de uma aula para outra, ou seja, o famoso recreio, o qual pode ser de 10, 15 ou 20 minutos, é vislumbrado como tempo no qual o professor estar a disposição do empregador, devendo ser remunerado, portanto ${ }^{21}$.

Deve-se acrescentar o adicional hora extra, em relação ao tempo do recreio quando ultrapassar as quatro aulas consecutivas ministradas pelo professor.

O direito a hora extra do professor, decorrente do recreio, vem explicitado na jurisprudência do Tribunal Superior do Trabalho:

\footnotetext{
${ }^{20}$ Consolidação das Leis do Trabalho. Art. 4o - Considera-se como de serviço efetivo o período em que o empregado esteja à disposição do empregador, aguardando ou executando ordens, salvo disposição especial expressamente consignada. Precedente no 31 do Tribunal Superior do Trabalho - Os tempos vagos (janelas) em que o professor ficar à disposição do curso serão remunerados como aula, no limite de 1 (uma) hora diária por unidade. (Diário de Justiça, 08-09-1992).

${ }^{21}$ RECURSO DE REVISTA PATRONAL. PROFESSOR. LIMITE DIÁRIO DE AULAS NUM MESMO ESTABELECIMENTO. AULAS CONSECUTIVAS. INTERVALO PARA RECREIO. ART. 318 DA CLT. O intervalo relativo ao recreio não importa em interrupção da jornada de trabalho do professor. Por ser bem limitado, não permite ao profissional, sequer, deixar o seu local de trabalho, entregando-se a tarefas outras que não aquelas de interesse do próprio empregador. Para fins de aplicação do art. 318 da CLT, consideram-se as duas aulas ministradas - antes e depois daquele intervalo - como sendo consecutivas. Revista conhecida, por divergência jurisprudencial, e desprovida" (Tribunal Superior do Trabalho - Recurso de Revista -1698200-51.2004.5.09.0004, 4a Turma, Relatora Ministra Maria de Assis Calsing, Diário Eletrônico da Justiça do Trabalho, 8/4/2011).

RECURSO DE REVISTA DA RECLAMANTE. 1) INTERVALO INTRAJORNADA. TEMPO À DISPOSIÇÃO. Os intervalos concedidos entre as aulas ministradas caracterizam tempo à disposição do empregador, nos termos do art. 40 da CLT, que assim dispõe: 'Considera-se como de serviço efetivo o período em que o empregado esteja à disposição do empregador, aguardando ou executando ordens, salvo disposição especial expressamente consignada.' Recurso de revista conhecido e provido" (Tribunal Superior do TrabalhoRecurso de Revista-1498500-39.2005.5.09.0011, 6a Turma, Relator Ministro Mauricio Godinho Delgado, Diário Eletrônico da Justiça do Trabalho, 16/12/2011).
} 
RECURSO DE REVISTA DA RECLAMADA. PROFESSOR. HORAS EXTRAS. INTERCALAÇÃO. RECREIO. Nos termos do artigo 318 da CLT, o professor, em um mesmo estabelecimento de ensino, não poderá ministrar, por dia, quatro aulas consecutivas, nem mais de seis, intercaladas, sendo que o intervalo para recreio, por não permitir o desenvolvimento pelo professor das demais atividades curriculares, não descaracteriza a jornada consecutiva, devendo, portanto, serem remuneradas como extras as aulas a partir da quarta consecutiva. Recurso de revista conhecido e não provido".

\subsubsection{DO TRABALHO NOTURNO}

Tendo em vista o desgaste acentuado aos que laboram no horário noturno, logicamente, sendo um laborar em condições mais gravosas. A Constituição Federal garantiu uma remuneração diferenciada aos trabalhadores que lavoram no horário noturno ${ }^{23}$, vindo a Consolidação das Leis do Trabalho determinar um adicional de $20 \%$ sobre a hora diurna ${ }^{24}$.

É considerado trabalho noturno aqueles executados entre às $22 \mathrm{~h} 00 \mathrm{~min}$ a $05 \mathrm{~h} 00 \mathrm{~min}$ do dia seguinte, para o trabalhador urbano.

Ou seja, o professor que tem seu horário de aula encerrado às 22 h 15 min; 22h2omin; 22 h30 min; por exemplo, tem direito a receber o adicional de 20\% sobre os $15 \mathrm{~min}$; $20 \mathrm{~min}$; 30 min; trabalhados após as 22 hoo min horas (Barros, 2011, p 565).

Segue decisão do Tribunal Superior do Trabalho sobre a matéria:

"Com efeito, prevê o artigo 73 da CLT, in verbis: "Salvo nos casos de revezamento semanal ou quinzenal, o trabalho noturno terá remuneração superior a do diurno e, para esse efeito, sua remuneração terá um acréscimo de 20 \% (vinte por cento), pelo menos, sobre a hora diurna". Segundo o dispositivo, o labor em horário noturno deve ser remunerado com o adicional de $20 \%$ sobre a hora diurna. O parágrafo $2^{\mathrm{O}}$ do citado dispositivo, por sua vez, estabelece os parâmetros em relação ao horário noturno, nos seguintes termos: "Considera-se noturno, para os efeitos deste artigo, o trabalho executado entre as $\mathbf{2 2}$ horas de um dia e as 5 horas do dia seguinte". Nota-se que o dispositivo não exige que o adicional noturno incida apenas sobre o período completo de uma hora, após as 22 horas, como equivocadamente entendeu o Tribunal a quo. Na verdade, a exigência de que o adicional somente incida sobre hora completa no período noturno desconsidera a legislação trabalhista, que, como exposto, não faz nenhuma ressalva ao pagamento do adicional. Além disso, registra-

\footnotetext{
${ }^{23}$ Constituição Federal de 1988. Art. 70, IX - remuneração do trabalho noturno superior à do diurno;

${ }^{24}$ Consolidação das Leis do Trabalho. Art. 73. Salvo nos casos de revezamento semanal ou quinzenal, o trabalho noturno terá remuneração superior a do diurno e, para esse efeito, sua remuneração terá um acréscimo de 20 \% (vinte por cento), pelo menos, sobre a hora diurna.
} 
se que a Constituição Federal, no artigo $7^{\circ}$, inciso IX, garante ao trabalhador o direito à "remuneração do trabalho noturno superior à do diurno". Desse modo, o fato de o reclamante ter trabalhado em apenas 40 minutos no período noturno não afasta o seu direito à incidência do adicional sobre esse período. Recurso de revista conhecido e provido" ${ }^{25}$.

Vale ressaltar que o pagamento habitual do adicional noturno repercute no cálculo do $13^{\circ}$ salário, do $1 / 3$ de férias, devendo ser levado em conta para todos os efeitos legais. Tal posicionamento é matéria sumulada do Tribunal Superior do Trabalho ${ }^{26}$.

\subsection{DESCANSO ANUAL REMUNERADO - FÉRIAS}

Com o fim de preservar a higidez física e mental do trabalhador, além de permitir com convívio social e familiar mais duradouro a Convenção $\mathrm{n}^{0} 132$ da Organização Internacional do Trabalho, bem como a Constituição Federal garantem ao trabalhador um período de férias remuneradas ${ }^{27}$.

O direito de férias ocorre após um período de trabalho de 12 meses (período aquisitivo), podendo ser concedido pelo empregador a qualquer momento nos próximos 12 meses, no prazo de 30 dias, os quais serão remunerados com um terço a mais do que o salário normal.

Excepcionalmente, será possível fracionar as férias. Todavia, não poderá ser inferior a 10 dias.

A concessão das férias deve ser anotada na Carteira de Trabalho e Previdência Social ${ }^{28}$, além de o trabalhador ser comunicado do respectivo gozo, com uma antecedência de 30 dias, devendo dar contra recibo dessa comunicação ${ }^{29}$.

O trabalhador deve receber o pagamento da remuneração das férias até dois dias antes do início do respectivo período, para que o mesmo possa gozar efetivamente das mesmas ${ }^{30}$.

O desrespeito a prazo para concessão das férias acarreta o pagamento em dobro das mesmas $^{31}$. Não só o gozo das férias fora do prazo, como também, o pagamento da remuneração das férias fora do período legal, acarreta o pagamento em dobro, igualmente.

\footnotetext{
${ }^{25}$ Tribunal Superior do Trabalho. 2은 Turma, Recurso de Revista - 100800-15.2009.5.03.0098, relator ministro José Roberto Freire Pimenta, DETJ 02/08/2012.

${ }^{26}$ TRIBUNAL SUPERIOR DO TRABALHO. SÚMULA № 60 ADICIONAL NOTURNO. INTEGRAÇÃO NO SALÁRIO E PRORRO-GAÇÃO EM HORÁRIO DIURNO - Res. 129/2005, DJ 20, 22 e 25.04.2005 I - O adicional noturno, pago com habitualidade, integra o salário do empregado para todos os efeitos.

${ }^{27}$ Constituição Federal de 1988. Art. 70, XVII - gozo de férias anuais remuneradas com, pelo menos, um terço a mais do que o salário normal;

${ }^{28}$ Consolidação das Leis do Trabalho. Art. 135. § 10 - O empregado não poderá entrar no gozo das férias sem que apresente ao empregador sua Carteira de Trabalho e Previdência Social, para que nela seja anotada a respectiva concessão

${ }^{29}$ Consolidação das Leis do Trabalho. Art. 135 - A concessão das férias será participada, por escrito, ao empregado, com antecedência de, no mínimo, 30 (trinta) dias. Dessa participação o interessado dará recibo.

${ }^{30}$ Consolidação das Leis do Trabalho. Art. 145 - O pagamento da remuneração das férias e, se for o caso, o do abono referido no art. 143 serão efetuados até 2 (dois) dias antes do início do respectivo período.

31 Consolidação das Leis do Trabalho. Art. 137 - Sempre que as férias forem concedidas após o prazo de que trata o art. 134, o empregador pagará em dobro a respectiva remuneração.
} 
Tal entendimento se consubstancia na orientação jurisprudencial no 386 da Seção de Dissídios Individuais do Tribunal Superior do Trabalho:

Orientação jurisprudencial - Seção de Dissídios Individuais - $1 \mathrm{n}^{\circ} 386$ FÉRIAS. GOZO NAÉPOCA PRÓPRIA. PAGAMENTO FO-RA DO PRAZO. DOBRA DEVIDA. ARTS. 137 E 145 DA CLT.

É devido o pagamento em dobro da remuneração de férias, incluído o terço constitucional, com base no art. 137 da CLT, quando, ainda que gozadas na época própria, o empregador tenha descumprido o prazo previsto no art. 145 do mesmo diploma legal.

É permitido ao trabalhador converter até um terço do período de férias em pecúnia, desde que requerido até 15 dias antes do término do período aquisitivo ${ }^{32}$.

No intuito de garantir a convivência familiar, prescreve a Consolidação das Leis do Trabalho que os familiares que laboram para o mesmo empregador, terão direito a gozar as férias no mesmo período, desde que não gere prejuízos ao serviço ${ }^{33}$.

Todos esses preceitos gerais sobre férias aplicam-se, normalmente, ao professor, pois não há regra própria sobre a matéria para essa categoria.

\subsubsection{FÉRIAS ESCOLARES}

Durante as férias escolares, as quais ocorrem, geralmente, nos meses de janeiro, fevereiro ou julho, é garantido ao professor o seu salário correspondente. Esse é o teor da Súmula no 10 do Tribunal Superior do Trabalho:

\section{Professor - Pagamento dos Salários - Férias Escolares}

É assegurado aos professores o pagamento dos salários no período de férias escolares. Se despedido sem justa causa, ao terminar o ano letivo ou no curso dessas férias, faz jus aos referidos salários.

Durante esse recesso escolar o professor fica a disposição do empregador, todavia, só pode ser exigido atividades relacionada com exames e provas (Barros, 2012, p 382). Qualquer atividade, além disso, pode configurar hora extra ou mesmo desvio de função ${ }^{34}$.

\footnotetext{
32 Consolidação das Leis do Trabalho. Art. 143 - É facultado ao empregado converter 1/3 (um terço) do período de férias a que tiver direito em abono pecuniário, no valor da remuneração que lhe seria devida nos dias correspondentes. $\S 10$ - 0 abono de férias deverá ser requerido até 15 (quinze) dias antes do término do período aquisitivo.

${ }^{33}$ Consolidação das Leis do Trabalho. $\S 1$ 으 - Os membros de uma família, que trabalharem no mesmo estabelecimento ou empresa, terão direito a gozar férias no mesmo período, se assim o desejarem e se disto não resultar prejuízo para o serviço.

${ }^{34}$ Há relatos de instituições privadas que em época de recesso escolar obrigava professor a trabalhar na secretaria da instituição, na feitura de matrículas escolares.
} 


\subsection{DIREITO A REMUNERAÇÃO DO DESCANSO SEMANAL}

A Consolidação das Leis do Trabalho, no art. 67 assegura a todo empregado um descanso semanal remunerado de 24 (vinte e quatro) horas consecutivas, após seis dias de trabalho sucesso, o qual, salvo motivo de conveniência pública ou necessidade imperiosa do serviço, deverá coincidir com o domingo, no todo ou em parte.

Destaca-se, o fato que esse tempo de 24 horas soma-se às onze horas do intervalo interjornada, o que totaliza 35 horas de descanso, havendo súmula do Tribunal Superior do Trabalho sobre a matéria ${ }^{35}$.

O repouso semanal remunerado, também, é chamado de descanso hebdomadário (vem do grego e quer dizer semana).

Como delineado na Súmula 351 do Tribunal Superior do Trabalho, o professor remunerado por hora/aula tem o direito ao acréscimo de $1 / 6$ a título de repouso semanal, tendo como base o mês com quatro semanas e meia, segundo dispõe o art. $320, \S 1^{\circ}$ da Consolidação das Leis do Trabalho.

De tal sorte segue a transcrição da Súmula 351 do Tribunal Superior do Trabalho:

SUM-351 PROFESSOR. REPOUSO SEMANAL REMUNERADO. ART. $7^{\circ}, \S 2^{\circ}$, DA LEI No 605, DE 05.01.1949 E ART 320 DA CLT (mantida).

O professor que recebe salário mensal à base de hora-aula tem direito ao acréscimo de $1 / 6$ a título de repouso semanal remunerado, considerando-se para esse fim o mês de quatro semanas e meia.

Chama-se a atenção a prática vedada do salário compressivo, no qual o empregador engloba numa única rubrica o pagamento de diversas parcelas. De tal maneira, explicita a súmula 91 do Tribunal Superior do Trabalho:

\section{SUM-91 SALÁRIO COMPLESSIVO}

Nula é a cláusula contratual que fixa determinada importância ou percentagem para atender englobadamente vários direitos legais ou contratuais do trabalhador.

Torna-se palmar, a ilegalidade de muitas instituições de ensino que tentam burlar os imperativos juslaborais, incutindo no valor da hora/aula a remuneração do descanso semanal ${ }^{36}$.

Por fim, como dispõe o art. 319 da Consolidação das Leis do Trabalho, é proibido aos professores, aos domingos, a regência de aulas e o trabalho em exames.

\footnotetext{
${ }^{35}$ SUM-110 JORNADA DE TRABALHO. INTERVALO - Res. 121/2003, DJ 19, 20 e 21.11.2003

No regime de revezamento, as horas trabalhadas em seguida ao repouso semanal de 24 horas, com prejuízo do intervalo mínimo de 11 horas consecutivas para descanso entre jornadas, devem ser remuneradas como extraordinárias, inclusive com o respectivo adicional.

${ }^{36}$ Consolidação das Leis do Trabalho. Art. 9o - Serão nulos de pleno direito os atos praticados com o objetivo de desvirtuar, impedir ou fraudar a aplicação dos preceitos contidos na presente Consolidação.
} 


\subsection{REMUNERAÇÃO}

A remuneração do professor é aferida mensalmente, tendo por base o número de aulas ministradas semanalmente, vezes 4,5 semanas e meia, para aferir o seu salário ${ }^{37}$.

Apreenda que a natureza jurídica da remuneração é de caráter alimentar, sendo assim, a Constituição Federal e na legislação infraconstitucional prevê diversos instrumentos de proteção ao salário do trabalhador.

A Constituição garante a irredutibilidade salarial; a Consolidação das Leis do Trabalho prevê que o salário deve ser pago ate o quinto dia útil, não podendo o prazo de pagamento ser estipulado para período superior a um mês, devendo ser efetuado no local do trabalho, sendo vedados descontos; o Código de Processo Civil determina pela impenhorabilidade dos salários no processo de execução; a lei de falência privilegia as verbas trabalhistas no concurso de credores em relação os demais créditos.

No que tange a irredutibilidade salarial, a qual foi galgada a status de garantia constitucional ${ }^{38}$, destaca Delgado:

Note-se, portanto, que a noção de irredutibilidade busca combater duas modalidades centrais de diminuição de salários: a redução salarial direta (diminuição nominal de salários) e a redução salarial indireta (redução da jornada ou do serviço, com consequente redução salarial). Como enfatizado, tais modalidades são, em princípio, vedadas pela ordem jurídica, podendo ensejar, conforme o caso, até mesmo a rescisão do contrato por culpa empresarial (art. 483, d e g, CLT) (Delgado, 2008, p. 729).

Torna-se palmar a violação da garantia a irredutibilidade salarial, constituindo exercício lícito do jus variandi do empregador quando o mesmo reduz o número de turmas do professor, sem ter havido a diminuição do número de alunos ${ }^{39}$, constituindo uma forma de rescisão indireta do contrato de trabalho, pois apesar de não ter havido a redução do valor da horaaula, a remuneração será menor pelo número menor de aulas.

Geralmente tal prática é realizada pelas Instituições de Ensino Privado como forma de pressionar o professor a pedir rescisão do contrato de trabalho para que a mesma não tenha que arcar com o ônus das verbas rescisórias trabalhistas, vindo o docente a ter os seus direitos

\footnotetext{
${ }^{37}$ Consolidação das Leis do Trabalho. Art. 318. §1으 O pagamento far-se-á mensalmente, considerando-se para este efeito cada mês constituído de quatro semanas e meia.

${ }^{38}$ Constituição Federal. Art. 70 São direitos dos trabalhadores urbanos e rurais, além de outros que visem à melhoria de sua condição social: VI - irredutibilidade do salário, salvo o disposto em convenção ou acordo coletivo;

${ }^{39}$ Orientação jurisprudencial-seção de dissídios individuais 1-244 PROFESSOR. REDUÇÃO DA CARGA HORÁRIA. POSSIBILIDADE (inserida em 20.06.2001) A redução da carga horária do professor, em virtude da diminuição do número de alunos, não constitui alteração contratual, uma vez que não implica redução do valor da hora-aula.
} 
ceifados, como por exemplo, a multa de $40 \%$ dos valores depositados a título de fundo de garantia de tempo de serviço e o direito de saque do respectivo benefício social ${ }^{40}$.

Destacar que a mora contumaz no adimplemento das verbas salariais (oque caracteriza descumprimento das obrigações contratuais), seja não pagamento, seja pagando fora do prazo, é hipótese de rescisão indireta do contrato de trabalho como previsto no art. 483, "d" da Consolidação das Leis do Trabalho (Delgado, 2011, p 1162).

De tal sorte, as instituições de ensino que não efetuarem o pagamento dos professores até o quinto dia útili ${ }^{41}$, acarreta ao docente o direito a rescisão do contrato sem justa causa, fazendo jus a todas as verbas rescisórias.

\subsubsection{DÉCIMO TERCEIRO SALÁRIO}

A respectiva verba salarial compulsória é regida pelas Leis nº 4.090/62 (Institui a Gratificação de Natal para os Trabalhadores) e n ${ }^{0}$ 4.749/65 (Dispõe sobre o Pagamento da Gratificação Prevista na Lei n ${ }^{0} 4.090 / 62$ ), além do Decreto Executivo de $n^{0}$ 57.155/65 (Expede nova regulamentação da Lei $n^{0} 4.090 / 62$, que institui a gratificação de Natal para os trabalhadores, com as alterações introduzidas pela Lei $\mathrm{n}^{\mathrm{O}} 4 \cdot 749 / 65$ 1965), o qual regulamente as leis em tela.

No que tange ao assunto trazido a baila, aplica-se ao professor as determinações gerais explicitados em tais normas.

De tal sorte, fica garantindo o recebimento do $13^{\circ}$ salário até o dia 20 dezembro, sendo obrigatório o adiantamento dessas versa salarial, correspondente à metade do seu valor, entre os meses de fevereiro a novembro, ficando a cargo de o empregador pagar o mês da sua conveniência, não estando obrigado a efetuar o adimplemento dessas versa trabalhista a todos os empregados simultaneamente ${ }^{42}$.

\footnotetext{
${ }^{40}$ Descrição de tal prática retirado de sentença referente aos autos processuais no 120000-55.2010.5.21.0006, do Tribunal Regional do Trabalho da 21으 região: "Relata o reclamante em petição inicial ter sido admitido como professor do curso de direito, para trabalhar em período integral (40 horas hebdomadárias), por possuir título de Doutor em Direito, em conformidade com o art. 52, II e III, da Lei 9.364/96, que exige que 1/3 dos docentes possuam titulação de mestrado ou doutorado. Diz ainda ter sido convidado a criar, compor e editar a Revista ......, tendo durante 4 anos coordenado 14 doutores em Direito, na produção de pesquisa científica de acordo com exigências da CAPES. Aduz, ainda, que o projeto de criação do curso de Mestrado em Direito não foi aprovado, por responsabilidade exclusiva da reclamada, que o comprou de um consultor de fora da instituição, sem qualquer aderência com a produção intelectual e acadêmica dos doutores da instituição. Sustenta também que a reclamada foi comprada por uma multinacional americana denominada......, que teria implantado política de produção fabril e demitido parte dos professores doutores anteriormente contratados. Narra, por derradeiro que a reclamada, de forma unilateral, diminuiu drasticamente a carga horária dos doutores, sendo que o reclamante em julho e agosto/2010 teria passado de 40 para 14 horas semanais, embora suas atribuições tivessem permanecido inalteradas. Propugna, por consequência, da declaração de rescisão indireta do contrato de trabalho, com arrimo nas alíneas d e g do artigo 483, da Consolidação das Leis do Trabalho".

Disponívelem: http://www.trt21.jus.br/asp/jurisprudencia/mostradoc.asp?codigodoc=148670\&TipoFonte=Sentencas\&MimeType=. Acessado em: 01 de setembro de 2013.

${ }^{41}$ Segundo a IN 1/89 do MTPS, o sábado é contado como dia útil. (Delgado, 2008, p. 737). (Cassar, 2011, p. 929).

${ }^{42}$ Art. 2으, § 2 ㅇ da Lei № 4.090/62.
} 
Todavia, fica ao empregado a opção de solicitar o pagamento do adiantamento da primeira parcela do $13^{\circ}$ salário a ser pago quando das férias, desde que solicitado no mês de janeiro do respectivo ano de gozo das férias ${ }^{43}$.

Sobre a gratificação natalina será descontado os valores referente ao fundo de garantia de tempo de serviço, imposto de renda e a contribuição social do empregado para financiamento da previdência social ${ }^{44}$.

$\mathrm{O} 13^{\circ}$ salário será calculado levando em conta a remuneração de dezembro e todas as verbas salariais pagas habitualmente ${ }^{45}$, vindo essa gratificação corresponder a 1/12 da remuneração mensal (ou fração superior a 14 dias), para cada mês de serviço do ano correspondente ${ }^{46}$.

\subsubsection{GRATIFICAÇÃO POR TEMPO DE SERVIÇO}

É uma verba salarial espontânea, não havendo lei que imponha o pagamento, sendo devido quando o empregado/professor preencha certas condições: tempo de serviço na empresa (anuênio, biênio ou quinquênio).

Tendo natureza de verba salarial deve integrar a remuneração para todos os efeitos, como férias, 13 salário, etc ${ }^{47}$.

Atente que a alteração contratual da gratificação por tempo de serviço de anuênio para biênio ou de biênio para quinquênio é proibido por ser prejudicial ao empregado ${ }^{48}$.

\subsection{INTERRUPÇÃO DO CONTRATO DE TRABALHO}

O art. 473 da Consolidação das Leis do Trabalho prevê as seguintes hipóteses de interrupção do contrato de trabalho, sem prejuízo da remuneração:

\footnotetext{
${ }^{43}$ Art. 2o, § 3ㅇ da Lei no 4.090/62.

${ }^{44}$ Constituição Federal. Art. 195. A seguridade social será financiada por toda a sociedade, de forma direta ... II - do trabalhador e dos demais segurados da previdência social, não incidindo contribuição sobre aposentadoria e pensão concedidas pelo regime geral de previdência social de que trata o art. 201;

${ }^{45}$ TRIBUNAL SUPERIOR DO TRABALHO. SUM-45 SERVIÇO SUPLEMENTAR (mantida) - Res. 121/2003, DJ 19, 20 e 21.11.2003. A remuneração do serviço suplementar, habitualmente prestado, integra o cálculo da gratificação natalina prevista na Lei no 4.090, de 13.07.1962; SUM-60 ADICIONAL NOTURNO. INTEGRAÇÃO NO SALÁRIO E PRORROGAÇÃO EM HORÁRIO DIURNO (incorporada a Orientação Jurisprudencial no 6 da SBDI-1) - Res. 129/2005, DJ 20, 22 e 25.04.2005. I - O adicional noturno, pago com habitualidade, integra o salário do empregado para todos os efeitos. (ex-Súmula no 60 - RA 105/1974, DJ 24.10.1974)...; SUM-139 ADICIONAL DE INSALUBRIDADE (incorporada a Orientação Jurisprudencial no 102 da SBDI-1) - Res. 129/2005, DJ 20, 22 e 25.04.2005. Enquanto percebido, o adicional de insalubridade integra a remuneração para todos os efeitos legais. (exOJ no 102 da SBDI-1 - inserida em 01.10.1997); SUM-354 GORJETAS. NATUREZA JURÍDICA. REPERCUSSÕES (mantida) - Res. 121/2003, DJ 19, 20 e 21.11.2003. As gorjetas, cobradas pelo empregador na nota de serviço ou oferecidas espontaneamente pelos clientes, integram a remuneração do empregado, não servindo de base de cálculo para as parcelas de aviso-prévio, adicional noturno, horas extras e repouso semanal remunerado.

${ }^{46}$ Art. 1으, § 20 da Lei no 4.090/62.

47 TRIBUNAL SUPERIOR DO TRABALHO. SUM-203 GRATIFICAÇÃO POR TEMPO DE SERVIÇO. NATUREZA SALA-RIAL (mantida) Res. 121/2003, DJ 19, 20 e 21.11.2003. A gratificação por tempo de serviço integra o salário para todos os efeitos legais. ${ }^{48}$ Consolidação das Leis do Trabalho. Art. 468 - Nos contratos individuais de trabalho só é lícita a alteração das respectivas condições por mútuo consentimento, e ainda assim desde que não resultem, direta ou indiretamente, prejuízos ao empregado, sob pena de nulidade da cláusula infringente desta garantia.
} 
I - até 2 (dois) dias consecutivos, em caso de falecimento do cônjuge, ascendente, descendente, irmão ou pessoa que, declarada em sua carteira de trabalho e previdência social, viva sob sua dependência econômica; (grifos nossos).

II - até 3 (três) dias consecutivos, em virtude de casamento;

III - por um dia, em caso de nascimento de filho no decorrer da primeira semana; IV - por um dia, em cada 12 (doze) meses de trabalho, em caso de doação voluntária de sangue devidamente comprovada;

V - até 2 (dois) dias consecutivos ou não, para o fim de se alistar eleitor, nos têrmos da lei respectiva.

VI - no período de tempo em que tiver de cumprir as exigências do Serviço Militar referidas na letra "c" do art. 65 da Lei no 4.375, de 17 de agosto de 1964 (Lei do Serviço Militar).

VII - nos dias em que estiver comprovadamente realizando provas de exame vestibular para ingresso em estabelecimento de ensino superior.

VIII - pelo tempo que se fizer necessário, quando tiver que comparecer a juízo. IX - pelo tempo que se fizer necessário, quando, na qualidade de representante de entidade sindical, estiver participando de reunião oficial de organismo internacional do qual o Brasil seja membro.

Chama-se a atenção, no que tange ao professor, que o prazo em caso de casamento ou falecimento do cônjuge, ascendentes ou filho será de nove dias, como prevê o art. 320 , § $3^{\circ}$ da Consolidação das Leis do Trabalho, regra específica e mais benéfica.

Destarte, não se aplica a regra geral do art. 473, I e II da Consolidação das Leis do Trabalho, que prevê três dias no caso de casamento e dois dias no caso de falecimento dos parentes dependentes economicamente, registrados na carteira de trabalho e previdência social.

\section{CONSIDERAÇÕES FINAIS}

O professor é um dos protagonistas, indispensáveis, do processo educacional, o qual visa à transferência de um conhecimento e de uma autonomia crítica desse conhecimento para o discente, permitindo que este, mais que um técnico em algum dos saberes da humanidade, possa torna-se um cidadão.

De tal sorte, torna-se necessário o processo de revalorização desse profissional, seja na rede pública ou na rede privada, como peça fulcral do desenvolvimento e expansão de uma educação com qualidade. 
Um aspecto nesse processo de revalorização do docente, analisado no trabalho em tela, dá-se no aspecto do respeito às garantias trabalhistas, de tal maneira, que o mesmo possa ser remunerado condignamente, bem como preservado a sua saúde.

A justa remuneração configura o respeito e reconhecimento de uma classe trabalhadora, de tal sorte, a proporcionar a satisfação dos mesmos no exercício do oficio, bem como estímulo para outras pessoas busquem essa carreira, evitando, assim, a escassez da mão-de-obra.

A efetivação dos direitos trabalhistas propugnados em normas constitucionais, infralegais e convencionais permite que o professor tenha uma qualidade de vida que lhe proporcione desenvolver-se no ofício da educação de forma que esta se desenvolva com qualidade, pois terá o docente estimulado, renovado e compromissado com a atividade educacional.

Constatou-se, no estudo em tela, que o professor é detentor do direito ao adicional noturno, quando lavorar depois das 22hoomin; que deve ser remunerado pelo tempo "livre" entre a espera de uma aula e outra (chamadas "janelas"); que o tempo posto a disposição da instituição de ensino, seja para reuniões, atender alunos, fora do horário de aula, deve ser remunerado com horas extras; que o desrespeito ao intervalo de 11 horas intrajornada acarreta o direito a receber horas extras; de que o professor só pode ministra seis aulas diárias numa mesma instituição de ensino, sendo possível, apenas, que quatro aulas sejam lecionadas continuamente, onde o desrespeito a essa norma acarreta o direito a percepção de horas-extras; que o não pagamento da remuneração até o quinto dia útil, bem como a redução indevida das horas aulas, quando não seja pela redução do número de alunos, pode acarretar a rescisão indireta do contrato de trabalho; que o professor deve receber a remuneração do repouso semanal equivalentes a 1/6 das horas aulas ministradas; e que o pagamento das férias em prazo posterior há dois dias, antes do gozo, gera o direito ao recebimento dobrado do descanso anual remunerado.

Espera-se que o presente artigo possa conscientizar a categoria dos professores sobre as garantias sociais que a Constituição Federal e a Consolidação das Leis do Trabalho lhe proporcionem, para que possam pleitear o cumprimento delas, seja de forma extrajudicial, seja junta a justiça trabalhista.

\section{REFERÊNCIAS BIBLIOGRÁFICAS}

Aranha, M. L. (2012). Filosofia da Educação. São Paulo: Moderna.

Barros, A. M. (2011). Curso do Direito do Trabalho (7º ed.). São Paulo: LTR.

Barros, A. M. (2012). Contratos e regulamentações especiais de trabalho ( $5^{\circ}$ ed.). São Paulo: LTR. 
Cassar, V. B. (2011). Direito do Trabalho (5º ed.). Rio de Janeiro: Impetus.

Delgado, M. G. (2008). Curso do direito do trabalho (10º ed.). São Paulo: LTR.

Dourado, L. F. (2011). O Plano Nacional de Educação como política de Estado: antecedentes históricos, avaliação e perspectivas. Em Plano Nacional de Educação (20112020): avaliação e perspectivas ( $2^{\circ}$ ed., pp. 17-59). Belo Horizont: Autêntica Editora.

Junior, J. C. (2011). Curso do Direito do Trabalho (6º ed.). Salvador: Juspodivm.

Martins, S. P. (2004). Direito do trabalho (13ํ ed.). São Paulo: Atlas.

Mello, M. B. (2010). Professor Universitário. Em Contratos especiais de trabalho (pp. 190-200). São Paulo: LTR.

\section{CURRÍCULUM VITAE}

\section{Rocco Antonio Rangel Rosso Nelson}

Especialista em Direito e Cidadania pela Escola Superior do Ministério Público. Especialista em Direito Penal e Criminologia pela Universidade Potiguar. Mestre em Direito Constitucional pela UFRN. Ex-Professor de Direito da UNIFACEX. Atualmente, professor de Direito, no Instituto Federal do Rio Grande do Norte - IFRN (Natal/Brasil).

rocco.nelson@ifrn.edu.br

\section{Rafael Laffitte Fernandes}

Especialista em Ética pela Universidade Federal do Rio Grande do Norte. Especialista em Direito Penal e Criminologia pela Universidade Potiguar. Mestre em Ciências Sociais pela UFRN. Atualmente, professor de Direito, no Instituto Federal do Rio Grande do Norte IFRN (Natal/Brasil).

laffitte_fernandes@hotmail.com

\section{Maria Soares De Macêdo}

Especialista em Pesquisa Científica e Metodologia do Ensino Superior. Mestra em Engenharia de Produção pela UFSC. Doutora em Ciências da Educação pela Universidade Americana de Assunção-PY. Técnica em Audiovisuais. Atualmente Coordenadora de Projetos e Relações Comunitárias do IFRN - Câmpus Natal Central - Brasil.

maria.soares@ifrn.edu.br 